\title{
Renal replacement therapy after repair of congenital heart disease in children
}

\author{
A comparison of hemofiltration and peritoneal dialysis
}

The development of renal failure necessitating peritoneal dialysis after cardiac operations is associated with a reported mortality greater than $\mathbf{5 0 \%}$. Improved fluid removal and nutritional support have been reported with the use of continuous arteriovenous hemofiltration and continuous venovenous hemofiltration techniques. We have compared our experience with all three techniques in managing children who required renal replacement therapy after cardiac operations in terms of efficacy (fluid removal, calorie intake, and clearance of urea and creatinine), complications, and outcome. Over a 5-year period renal replacement therapy was initiated in $\mathbf{4 2}$ children, and in $\mathbf{3 4}$ of them it was successfully established for more than a 24-hour period: 17 were managed with peritoneal dialysis, 8 with continuous arteriovenous hemofiltration, and 9 with continuous venovenous hemofiltration. A net negative fluid balance was achieved in only 6 (35\%) patients treated with peritoneal dialysis compared with $50 \%$ of those treated with continuous venovenous hemofiltration and $89 \%$ of those treated with continuous venovenous hemofiltration. In terms of nutritional support, calorie intake increased by $43 \%$ after peritoneal dialysis was started compared with $515 \%$ and $409 \%$ in the arteriovenous and venovenous hemofiltration groups, respectively, $(p<0.005)$. The serum urea levels fell by $36 \%(p=0.02)$ and $39 \%(p=0.005)$ compared with pre-therapy levels with arteriovenous and venovenous hemofiltration, respectively, and the creatinine content was reduced by $19 \%$ and $33 \%(p=0.003)$. Neither parameter was reduced in the peritoneal dialysis group. We conclude that the use of hemofiltration as a renal replacement therapy after surgical correction of congenital heart disease offers significant advantages over the more traditional approach of peritoneal dialysis. In addition, we suggest that a more aggressive approach to the management of fluid overload and nutritional depletion with hemofiltration may result in a decrease in the very high mortality seen in renal failure after cardiac operations. (J THORAC CARDIOVASC SURG 1995;109:322-31)

Fiona Fleming, MD, FRCPC, Desmond Bohn, MB, FRCPC, Helen Edwards, RN, Peter Cox, MB, FRCPC, Dennis Geary, MB, FRCPC, Brian W. McCrindle, MD, FRCPC, and William G. Williams, MD, FRCSC, Toronto, Ontario, Canada

$\mathrm{R}$ enal insufficiency after cardiac operations in children as manifested by oliguria and a positive fluid balance is relatively common. Although in

From the Pediatric Intensive Care Unit and the Divisions of Nephrology, Cardiology, and Cardiac Surgery, The Hospital for Sick Children, Toronto, and the Departments of Anesthesia, Pediatrics and Surgery, The University of Toronto, Toronto, Ontario, Canada.

Received for publication Feb. 9, 1994.

Accepted for publication Sept. 29, 1994.

Address for reprints: D. J. Bohn, MB, FRCPC, Department of Critical Care Medicine, The Hospital for Sick Children, 555 University Avenue, Toronto, Ontario M5G 1X8, Canada.

Copyright (C) 1995 by Mosby-Year Book, Inc.

$0022-5223 / 95 \$ 3.00+0 \quad \mathbf{1 2 / 1 / 6 0 9 6 5}$ most instances the situation resolves with the use of diuretic therapy and inotropic support, if it does not, the resulting fluid overload together with the limitations placed on free water intake leads to severe restriction of nutritional support, hypervolemia, and electrolyte disturbances. The excess tissue and lung edema may also impede pulmonary gas exchange and postpone weaning from mechanical ventilation. Persisting oliguria accompanied by a rising creatinine concentration that cannot be reversed with diuretic therapy is an indication for renal replacement therapy in the form of either peritoneal dialysis (PD) or hemodialysis. In various series the rate of intervention with renal replacement therapy has been between $1.6 \%$ and $7.7 \%$ in patients who have 
had cardiotomy, with an overall survival of less than $50 \%{ }^{1-9} \mathrm{PD}$ has long been established as the primary form of renal replacement therapy after cardiac operations. ${ }^{1-5,10-13}$ Far less experience with the use of short-term hemodialysis in this situation has been reported, apart from a single series of 11 patients with only a $30 \%$ survival. ${ }^{14}$ Neither of these modalities is entirely satisfactory. In the case of PD, it can be difficult to achieve a satisfactory negative fluid balance, even with a surgically placed Tenckhoff catheter (Accurate Surgical Instruments Corp., Toronto, Ontario, Canada), because of either leakage around the insertion site or inadequate peritoneal perfusion, whereas hemodialysis can remove fluid only on an intermittent basis and not infrequently results in hemodynamic instability. More recently, continuous hemofiltration modalities for renal replacement therapy have been used in preference to both PD and intermittent hemodialysis in acute renal failure of various origins. The most commonly used technique, continuous arteriovenous hemofiltration $(\mathrm{CAVH})$, was first introduced into clinical use by Kramer and associates ${ }^{15}$ in 1977 as a system allowing for fluid and electrolyte correction. Several series have now been published that show that $\mathrm{CAVH}$ can successfully achieve a negative fluid balance in critically ill children with acute renal failure. ${ }^{16-24}$ In continuous venovenous hemofiltration $(\mathrm{CVVH})$, on the other hand, a double-lumen venous catheter is used and replaces the need for arterial access, and a roller pump is placed between the afferent venous line and the filter to provide the necessary driving pressure. Although CVVH has been in clinical use since the early 1980s, the first published series of patients managed with $\mathrm{CVVH}$ appeared in $1988 .{ }^{25}$ As with CAVH, the techniques and principles of $\mathrm{CVVH}$ also lent themselves to the management of acute renal failure in the pediatric intensive care unit (ICU), and increasing experience has now been gained in the use of the technique in a variety of conditions giving rise to acute renal failure. ${ }^{26-29}$

In an attempt to determine the optimal management of patients with acute renal failure after cardiopulmonary bypass, we have undertaken a retrospective review of our experience with PD and $\mathrm{CAVH}$, which were used before the introduction of $\mathrm{CVVH}$, and compared it with a prospective series of patients treated with CVVH during the past 5 years in the Pediatric Intensive Care Unit at the Hospital for Sick Children. In particular we focused our review on fluid and electrolyte balance, caloric intake, and cost and complications of therapy.

\section{Patients and methods}

Data were collected retrospectively for all patients managed with PD and CAVH after cardiac operations and prospectively for the CVVH group. In all cases the indications for renal replacement therapy included one or more of the following: (1) anuria or oliguria (urine output $<0.5 \mathrm{ml} / \mathrm{kg}$ per hour) for 12 hours or more, (2) fluid overload with tissue edema not responsive to diuretic therapy, (3) hyperkalemia (potassium concentration $>5$ $\mathrm{mmol} / \mathrm{L}$ ), and (4) the necessity for intravenous nutrition in the presence of decreased renal function and positive fluid balance.

Demographic data collected included age, weight, and sex. The clinical condition of each patient, including the need for mechanical ventilation or inotropic support, hemodynamic stability, and other organ system failure, was recorded. Caloric intake and daily fluid balance were recorded before the start of renal replacement therapy and for up to 3 days after the initiation of therapy, as were biochemical parameters including urea, creatinine, potassium, and phosphate concentrations. In addition, note was made daily of any fluctuations in the patients' core temperatures (rectal or esophageal) and of the complete blood count.

Once initiated, the success or failure of renal replacement therapy was evaluated on the basis of (1) fluid removal, (2) electrolyte status, (3) change in serum creatinine and urea concentration, (4) caloric intake compared before and after initiation of renal replacement therapy, (5) complications related to renal replacement therapy, and (6) clinical outcome. In addition, in patients treated by either CAVH or CVVH, note was made of the number of filter changes necessary and the resulting cost per patient day.

PD. PD was performed after surgical placement of a tunneled Tenckhoff catheter or a Cook pediatric PD catheter (Cook Group Co., Bloomington, Ind.) and attachment to dialysis tubing (Travenol Inc., Mississauga, Ontario, Canada). The dialysate fluid used was Dianeal solution, $1.5 \%$ to $4.25 \%$ (Baxter Healthcare Corp., Deerfield, IIl.), to which heparin and cefazolin were added. Volumes of dialysate ranged from $10 \mathrm{ml} / \mathrm{kg}$ to $30 \mathrm{ml} / \mathrm{kg}$, with dwell times of 30 minutes to 2 hours. Potassium or sodium bicarbonate was added to the Dianeal solution when warranted on the basis of the biochemical profile of the individual patient. PD was managed by the nephrology staff in conjunction with the pediatric ICU staff, who were ultimately responsible for overall fluid management and nutritional control for the patient. The pediatric ICU nursing staff assumed responsibility for the day to day operation of the PD system. The principles and practice governing PD have been reviewed elsewhere. ${ }^{10}$

Technical principles of hemofiltration. Hemofiltration is an extracorporeal form of renal replacement therapy that uses convection rather than diffusive transport for solute and fluid removal. The flow of ultrafiltrate fluid through the highly permeable hemofilter is governed by a hydrostatic pressure gradient. In the case of CAVH this is 
Table I. Guidelines for blood flow and predilution fluid flow for $\mathrm{CVVH}$

\begin{tabular}{|c|c|c|c|}
\hline $\begin{array}{c}\text { Weight } \\
(\mathrm{kg})\end{array}$ & $\begin{array}{c}\text { Blood } \\
\text { flow } \\
(\mathrm{ml} / \mathrm{min})\end{array}$ & $\begin{array}{c}\text { Predilution } \\
\text { flow } \\
(\mathrm{ml} / \mathrm{hr})\end{array}$ & $\begin{array}{c}\text { Maximum } \\
\text { ultrafiltrate } \\
\text { removal } \\
(\mathrm{ml} / \mathrm{hr})\end{array}$ \\
\hline$<10$ & 50 & $200-400$ & 750 \\
\hline $10-20$ & 80 & $300-650$ & 1200 \\
\hline$>20$ & 150 & $600-1000$ & 2250 \\
\hline
\end{tabular}

arterial minus venous pressure; a mean arterial pressure of 50 to $60 \mathrm{~mm} \mathrm{Hg}$ is considered necessary to provide adequate hydrostatic pressure. In CVVH the pressure gradient across the filter is generated by the pumping mechanism. The volume of ultrafiltrate in either system can be controlled by altering the pressure in the ultrafiltrate line by passing the tubing through a gravimetric pump set to restrict the flow at a preselected rate. Plasma ultrafiltrate removal is balanced by a combination of a predilution electrolyte solution and intravenous alimentation fluid. A detailed account of the CAVH principles and technique used in the management of patients with congenital heart disease has recently been published. ${ }^{16}$ Arterial and venous vascular access was established and the cannulas were connected to hemofiltration tubing placed in line with the hemofilter. Dianeal $0.5 \%$ solution was used as a predilution replacement fluid and anticoagulation was maintained with heparin.

CVVH system. The principles of CVVH in critically ill patients have been reviewed elsewhere. ${ }^{30}$ The circuit in this instance was primed with a heparin-containing saline solution ( 5000 units $/ \mathrm{L})$, which was then rinsed out. The final prime was either blood or saline depending on patient size. Vascular access was obtained to a major vein (femoral, internal jugular, subclavian) via a percutaneous Seldinger technique, with the alternative route of a surgical cutdown used when the Seldinger technique failed. Either a Vascath (Vascath Inc., Mississauga, Ontario, Canada) or Quinton (Quinton Instrument Co., Seattle, Wash.) double-lumen cannula of appropriate size for patient age and weight was placed. The cannula was connected to hemofiltration tubing (Hospal, Basel, Switzerland). The venous inflow through the "arterial" lumen was passed to a roller pump (BSM 22, Hospal). An intravenous electrolyte solution ( $0.5 \%$ Dianeal solution) was introduced as a predilution fluid connected to the circuit proximal to the pump. The amount of predilution fluid used depended on the patient's weight (Table I), with the limitation that the total should not be allowed to exceed $14 \%$ of the blood flow to the filter. Occasionally the clinical and biochemical profile of the patient necessitated the addition of potassium or bicarbonate to the predilution fluid. In the presence of a persistent metabolic acidosis the predilution fluid was changed to a bicarbonate/electrolyte solution. After the pump and before the filter, a second port in the inflow tubing allowed administration of a continuous infusion of heparin at a dose of 10 to 20 units $/ \mathrm{kg}$ per hour. The anticoagulation of the system was monitored by the activated clotting time (Hemochron, International Technidyne Corporation, Edison, N.J.). Activated clotting times were generally maintained in the range of 150 to 180 seconds. The dose of heparin used to keep the activated clotting times in this range varied from none (bleeding diatheses, coagulopathies) to 20 units $/ \mathrm{kg}$ per hour. Blood then passed through the hemofilter: Amicon diafilter 20 (Amicon division, WR Grace and Co., Beverly, Mass), Fresenius 40 (Fresenius, Bad Homburg, Germany), or CT 110 HG (Baxter Healthcare Ltd., Mississauga, Ontario, Canada). The amount of ultrafiltrate removed was regulated by a gravimetric pump (IVAC Corporation, San Diego, Calif.) attached to a side port of the filter. The amount of ultrafiltrate removed was based on the fluid balance status and stability of an individual patient. In addition, we adhered to the principle common to all hemofiltration systems that ultrafiltrate removal should not be allowed to exceed $25 \%$ of the blood flow to the filter, inasmuch as the negative pressure required to generate this amount of fluid would disrupt the filter. In practice, the amount of ultrafiltrate removal never approaches this level. The blood flow guidelines and predilution flows used are listed in Table I.

Blood returning to the patient after the filter via the "venous" lumen of the catheter passed through a drip chamber with an air bubble detector and finally a blood warmer (Hotline, Level 1 Technologies Inc., Rockland, Mass.). A pressure alarm detected increased venous resistance in the circuit. Once the system was connected to the patient, maintenance of the system was under the control of the bedside nurse and did not require specialized dialysis staff. Fluid balance was monitored hourly. All fluids added to or removed from the system were controlled by infusion pumps. The electrolyte status was monitored on a 4- to 6-hour basis. Urea, creatinine, and complete blood counts were routinely monitored twice a day.

Statistical analysis. Data are reported as mean plus or minus standard error of the mean. For each form of renal replacement therapy, pretreatment and posttreatment values were compared by means of Student's paired $t$ test. Multiple comparisons were performed by analysis of variance. Intergroup comparisons were made with Tukey's studentized range tests when a significant $F$ value was obtained. A $p$ value less than 0.05 was accepted as statistically significant.

\section{Results}

The charts of all patients managed with renal replacement therapy after cardiopulmonary bypass between July 1988 and December 1992 were reviewed. Twenty-four patients had PD and nine patients were managed with CAVH. Data on the management of PD were incomplete in three patients and these were excluded. From July 1991 to December 1992, data were collected prospectively for the 12 patients who underwent CVVH. All 42 patients underwent cardiac surgical procedures ne- 
cessitating cardiopulmonary bypass and aortic crossclamping. CAVH and CVVH were instituted in one patient each when PD failed. Demographic data from the three treatment groups are presented in Table II. The mortality rates were similar for the three groups with a range of $58 \%$ to $67 \%$. All but one of the surviving patients had return of normal renal function, broadly defined as a normal urea and creatinine values and adequate urine output on discharge from the pediatric ICU.

The time from the end of operation to the initiation of renal replacement therapy varied widely. The PD group had a mean time from surgery to initiation of dialysis of 2.5 days, with a range of 1 to 6 days. This interval was increased in the CAVH and CVVH groups to a mean of 10 days and 6.7 days, respectively. In both hemofiltration groups four patients began having renal replacement therapy more than 7 days after the operation. The duration of treatment also varied widely depending on the mode of renal replacement therapy. In the CAVH group the mean duration of therapy was 57 hours, whereas in the PD and CVVH groups the mean durations of therapy were longer, at 136 and 168 hours, respectively.

The percentage of patients requiring a second surgical procedure was similar in all three groups, ranging from $33 \%$ to $42 \%$ (see Table II). All but three patients were receiving inotropic support and $86 \%$ were receiving two cardiac support drugs or more in an attempt to maintain cardiovascular stability. Dopamine and/or dobutamine were the firstline inotropic agents in all patients managed with renal replacement therapy (Tables IIIA and IIIB). Sepsis was suspected or proved before the initiation of renal replacement therapy in 18 patients $(42 \%)$ and tended to be more prevalent in the patients treated with hemofiltration. Sepsis refers to the presence of a positive blood culture or the noting in the charts by the medical staff of the impression of sepsis (based on a combination of hemodynamic instability, hyperthermia, elevated or depressed neutrophil count with leftward shift, and thrombocytopenia).

Only those patients who successfully underwent a form of renal replacement therapy for more than 24 hours were analyzed with respect to fluid balance, caloric intake, biochemical analysis, and complications attributable to the renal replacement therapy. They comprised 17 of 21 patients in the PD group, 8 of 9 patients in the CAVH group, and 9 of 12
Table II. Demographic data for each group

\begin{tabular}{lccc}
\hline & $\begin{array}{c}P D \\
(n=21)\end{array}$ & $\begin{array}{c}C A V H \\
(n=9)\end{array}$ & $\begin{array}{c}C V W H \\
(n=12)\end{array}$ \\
\hline $\begin{array}{l}\text { Sex } \\
\text { Age (yr) }\end{array}$ & $13 \mathrm{M}: 8 \mathrm{~F}$ & $5 \mathrm{M}: 4 \mathrm{~F}$ & $7 \mathrm{M}: 5 \mathrm{~F}$ \\
$\quad$ Mean & 1.39 & 2.94 & 2.13 \\
$\quad$ Range & $1 \mathrm{wk}-11 \mathrm{yr}$ & 1 mo-9 yr & 1 wk-5.3 yr \\
Weight (kg) & & & \\
$\quad$ Mean & 6.71 & 11.43 & 9.23 \\
$\quad$ Range & $1.63-26.9$ & $2.9-20.9$ & $3.0-15$ \\
Preexisting renal disease & 0 & 3 & 0 \\
Survival & $8(38 \%)$ & $3(33 \%)$ & $5(42 \%)$ \\
Normal renal function in & $8(100 \%)$ & $2(67 \%)$ & $5(100 \%)$ \\
$\quad$ survivors & & & \\
Time postop (days) & & & \\
$\quad$ Mean & 2.5 & 10 & 6.7 \\
$\quad$ Range & $1-6$ & $2-30$ & $2-16$ \\
Duration (hr) & & & \\
$\quad$ Mean & 136 & 57 & 168 \\
$\quad$ Range & $4-360$ & $2-172$ & $14-312$ \\
Second surgical proce- & $7(33 \%)$ & $3(33 \%)$ & $5(42 \%)$ \\
$\quad$ dure & & & \\
Inotropic agents* & $19(90 \%)$ & $9(100 \%)$ & $12(100 \%)$ \\
Mechanical ventilation & $21(100 \%)$ & $9(100 \%)$ & $12(100 \%)$ \\
Sepsis & $6(28 \%)$ & $5(55 \%)$ & $7(58 \%)$ \\
\hline
\end{tabular}

*Patients receiving infusions of dopamine, epinephrine, and dobutamine, either singly or in combination.

patients in the CVVH group. The remaining 8 patients either died within 24 hours of the start of therapy or had recovery of renal function sufficient to allow the renal replacement therapy to be discontinued. In no case was the use of renal replacement therapy considered to be a contributary factor in the cause of death.

The fluid balances were compared between the groups on the basis of the net negative fluid balance achieved over the first 3 days of renal replacement therapy. In the PD group, 6 of the 17 patients (35\%) achieved a net negative fluid balance. The average fluid deficit was $9.2 \mathrm{ml} / \mathrm{hr}$, with a range of 3.5 to 26 $\mathrm{ml} / \mathrm{hr}$. Four of 8 patients $(50 \%)$ in the CAVH group had a net negative fluid balance, with an average fluid deficit to $23 \mathrm{ml} / \mathrm{hr}$ (range 3.9 to $34 \mathrm{ml} / \mathrm{hr}$ ). Finally, 8 of $9(89 \%)$ patients treated with CVVH reached net negative fluid balances, with an average deficit of $17.7 \mathrm{ml} / \mathrm{hr}$ (range 3.6 to $35 \mathrm{ml} / \mathrm{hr}$ ).

Nutritional status was assessed by recording caloric intake for 24 hours immediately before the institution of renal replacement therapy and then daily for the first 3 days of treatment. The posttreatment values were obtained by averaging the values for these 3 days. Similar data acquisition and calculations were undertaken for serum urea and creati- 
Table IIIA. Details of age, lesion operation, inotropic support, type of RRT, and access site for patients undergoing hemofiltration

\begin{tabular}{|c|c|c|c|c|c|}
\hline Age & $\begin{array}{l}\text { Cardiac } \\
\text { lesion }\end{array}$ & Operation & $\begin{array}{l}\text { Inotropic drugs } \\
(\mu g / \mathrm{kg} / \mathrm{min}) \\
\end{array}$ & $\begin{array}{c}\text { Type of } \\
\text { RRT }\end{array}$ & $\begin{array}{l}\text { Access } \\
\text { site }\end{array}$ \\
\hline $9 \mathrm{yr}$ & Pulm. atresia, VSD, AS & $\begin{array}{l}\text { Closure VSD, replacement ho- } \\
\text { mograft, aortic valvotomy }\end{array}$ & DOP 20/EPI 2 & CAVH & $\mathrm{FA} / \mathrm{FV}$ \\
\hline $1.8 \mathrm{yr}$ & TGA, DILV, PS, VSD & Fontan & DOP 5/AMR 5/EPI 10 & CAVH & $\mathrm{FA} / \mathrm{FV}$ \\
\hline $\mathrm{N}$ & VSD, coarctation & Repair coarctation, closure VSD & DOP 10/DOB 12.5 & CAVH & FA/FV \\
\hline $\mathbf{N}$ & VSD, aortic atresia & Repair coarctation, closure VSD & DOP 20/EPI 1.2/NOR 0.5 & $\mathrm{CAVH}$ & $\mathrm{FA} / \mathrm{FV}$ \\
\hline $4 \mathrm{yr}$ & Pulm. atresia, VSD & Conduit replacement, repair VSD & DOP 2.5 & CAVH & $\mathrm{FA} / \mathrm{FV}$ \\
\hline $3 \mathrm{yr}$ & Tetralogy, AVSD & Repair AVSD, RV-PA conduit & DOP 5/AMR 20/EPI 0.5 & CAVH & $\mathrm{FA} / \mathrm{FV}$ \\
\hline $7 \mathrm{yr}$ & Tetralogy, AVSD & Repair, closure residual VSD & DOP 10/EPI 1.0 & CAVH & $\mathrm{FA} / \mathrm{FV}$ \\
\hline $1.3 \mathrm{yr}$ & PS, VSD, PA sling & $\begin{array}{l}\text { Pulm. valvotomy, closure VSD, } \\
\text { tracheal resection }\end{array}$ & DOP 20 & CAVH & $\mathrm{FA} / \mathrm{FV}$ \\
\hline $3 \mathrm{yr}$ & $\begin{array}{l}\text { Pulm. atresia, VSD, single } \\
\text { coronary }\end{array}$ & $\begin{array}{l}\text { Closure VSD, RV-PA conduit, } \\
\text { RPA repair }\end{array}$ & DOP 20/EPI 0.8 & CAVH & $\mathrm{FA} / \mathrm{FV}$ \\
\hline $\mathrm{N}$ & DILV, TGA, VSD & Arterial switch, PA band & DOP 10/DOB 20/EPI 0.3 & CVVH & FV \\
\hline $\mathrm{N}$ & TGA, IVS & Arterial switch & DOP 10/EPI 1.8 & CVVH & IJV \\
\hline $\mathrm{N}$ & TGA, IVS & Arterial switch & DOP 20/EPI 1.2/NOR 1.2 & CVVH & FV \\
\hline $6 \mathrm{mo}$ & Anomalous coronary & Reimplantation & DOB 10/EPI 0.6 & CVVH & FV \\
\hline $5 \mathrm{yr}$ & Tetralogy & Repair & DOB 10/EPI $0.5 /$ NOR 0.1 & CVVH & FV \\
\hline $3.5 \mathrm{yr}$ & $\begin{array}{l}\text { Pulm. atresia, VSD, AP } \\
\text { collaterals }\end{array}$ & RV-PA conduit, VSD repair & DOP 15/EPI 0.5/NOR 0.4 & $\mathrm{CVVH}$ & IJV \\
\hline $2 \mathrm{yr}$ & DORV & Fontan & DOP $10 /$ ISP 0.15 & CVVH & FV \\
\hline $\mathrm{N}$ & AVSD & PA band & DOP 10/DOB 20/EPI 0.1 & CVVH & FV \\
\hline $4.5 \mathrm{yr}$ & DORV, PS & Biventricular repair & DOP $10 /$ EPI 0.4 & $\mathrm{CVVH}$ & FV \\
\hline $3 \mathrm{yr}$ & Tetralogy, AVSD & Repair Glenn shunt & DOP 15/EPI 0.1 & CVVH & IJV \\
\hline $9 \mathrm{mo}$ & Tetralogy & Repair & DOP 15 & CVVH & IJV \\
\hline $4.5 \mathrm{yr}$ & PS, VSD & Fontan & DOP 20 & CVVH & IJV \\
\hline
\end{tabular}

RRT, Renal replacement therapy; VSD, ventricular septal defect; $A S$, aortic stenosis; TGA, transposition of the great arteries; $D I L V$, double-inlet left ventricle; $P S$, pulmonary stenosis; $A V S D$, atrioventricular septal defect; $P A$, pulmonary artery; $I V S$, intact ventricular septum; $A P$, aortopulmonary; $D O R V$, double-outlet right ventricle; $R V$, right ventricle; $R P A$, right pulmonary artery; $D O B$, dobutamine; $E P I$, epinephrine; $A M R$, amrinone; $D O B$, dobutamine; $N O R$, norepinephrine; $I S P$, isoproterenol; $F A$, femoral artery; $F V$, femoral vein; $I J V$, internal jugular vein; $N$, newborn.

nine values. The pretreatment and posttreatment values for each of the groups with respect to these parameters are presented in Table IV. The percent change from baseline for each group is given, as well as being depicted graphically in Figs. 1 and 2 .

The caloric intake was spectacularly better in the hemofiltration groups than in the PD group. In all three groups the caloric intake before renal replacement therapy was extremely low, ranging from a mean of $13.5 \mathrm{Kcal} / \mathrm{kg}$ per day for the CAVH group to $24.2 \mathrm{Kcal} / \mathrm{kg}$ per day for the PD group. There was no significant difference between the groups before institution of renal support $(p=0.09)$. After treatment was begun, the caloric intake improved in all patient groups: in the PD group caloric intake increased by $43 \%$ to $34 \mathrm{Kcal} / \mathrm{kg}$ per day $(p=0.01)$, in the CAVH group by $515 \%$ to $80 \mathrm{Kcal} / \mathrm{kg}$ per day $(p=0.003)$, and in the CVVH group by $409 \%$ to 76 $\mathrm{Kcal} / \mathrm{kg}$ per day $(p<0.0001)$. There was a much larger caloric increase in the hemofiltration groups than in the PD group (CAVH $p<0.05$; CVVH $p<$ 0.05 ), whereas no significant difference was found when the two forms of hemofiltration were compared.

Clearance of urea and creatinine was much more efficient with hemofiltration than with PD. No statistical difference existed among the three groups before institution of therapy for either urea ( $p=$ $0.13)$ or creatinine $(p=0.62)$. Both hemofiltration groups showed a decline in the serum urea level, which fell by a mean of $36 \%$ in the CAVH group $(p=0.02)$ and $39 \%$ in the CVVH group $(p=0.005)$. Creatinine concentration declined by $19 \%$ in the CAVH group ( $p=$ no significant difference) and by $33 \%$ in the CVVH group ( $p=0.003)$ over the first 3 days of treatment. In contrast, the PD population demonstrated a slight rise in both parameters over the same time course ( $p=$ no significant difference). The percent decreases in serum urea content for the CAVH and CVVH groups were significant when compared with the percent change in the PD group $(p=0.001)$, and again no significant difference existed between the two forms of hemofiltration.

The total number of filters used was similar 
Table IIIB. Details of age, lesion operation, and inotropic support for patients undergoing PD

\begin{tabular}{|c|c|c|c|}
\hline Age & $\begin{array}{l}\text { Cardiac } \\
\text { lesion }\end{array}$ & Operation & $\begin{array}{l}\text { Inotropic dnugs } \\
(\mu \mathrm{g} / \mathrm{kg} / \mathrm{min})\end{array}$ \\
\hline $4.5 \mathrm{yr}$ & Pulm. atresia, VSD, TGA prior L-R BTS & Fontan & DOP 20/EPI 0.3 \\
\hline $3.5 \mathrm{yr}$ & Univent. heart, L-TGA, VSD, sub-PS & Fontan & DOP 6.5 \\
\hline $\mathrm{N}$ & Ao atresia, VSD & Repair VSD, PDA ligation, LV-Ao conduit & DOP 30/NOR 0.4/EPI 0.1/DOB 15 \\
\hline $\mathrm{N}$ & Coarctation, VSDs & Subclavian flap & \\
\hline $3.5 \mathrm{yr}$ & DILV, VSD, TGA & Fontan & DOP 20/EPI 0.2 \\
\hline $11 \mathrm{yr}$ & TAPVR, single atrium, PS & Fontan, RPA repair & DOP 5 \\
\hline $\mathbf{N}$ & TGA, VSD & PA band, Blalock-Hanlon & DOP 20/ISP 0.04/EPI 0.2 \\
\hline $\mathrm{N}$ & TGA, VSD, ASD, coarctation & Coarctation repair, PDA ligation & DOP 15/EPI 0.4 \\
\hline $\mathrm{N}$ & DORV, coarctation & Coarctation and arch repair & \\
\hline $\mathrm{N}$ & Coarctation, VSD & Coarctation repair & DOP 20/EPI 0.7 \\
\hline $3.5 \mathrm{yr}$ & DIRV, PS, AS, sub-PS & Fontan & DOP 15/EPI 0.2 \\
\hline $\mathrm{N}$ & HLHS & Norwood & EPI 1.0/DOP 5/AMR 15 \\
\hline $2 \mathrm{mo}$ & VSDs, ASD, Vent. arrhyth. & Repair ASD, VSD, PDA ligation & DOP 10 \\
\hline $1 \mathrm{mo}$ & AVSD & AVSD repair, PDA ligation & DOP 7.5/EPI 0.3 \\
\hline $\mathrm{N}$ & Pulm. atresia with IVS & PA-Ao shunt, patch RVOT & DOP 5 \\
\hline $3 \mathrm{mo}$ & TGA, VSD & PA band, BTS & AMR 20/EPI 0.3/DOP 5 \\
\hline $\mathrm{N}$ & Ao atresia, VSD, PFO & Arch repair, closure VSD, PFO, PDA & DOP 10/ISP 0.2/AMR 15 \\
\hline $\mathbf{N}$ & TGA, VSD & Switch, VSD repair & AMR 15/DOP 20/DOB 50/EPI 0.5 \\
\hline $\mathrm{N}$ & HLHS & Norwood & DOP 15/EPI 0.1 \\
\hline $2 \mathrm{yr}$ & DILV, VA discordance & Fontan & DOP 5/DOB 25/EPI 1.0 \\
\hline $\mathbf{N}$ & HLHS & Norwood & DOP 10 \\
\hline
\end{tabular}

$P D$, Peritoneal dialysis; $V S D$, ventricular septal defect; $T G A$, transposition of the great arteries; $P S$, pulmonary stenosis; Ao, aortic; $L-R B T S$, left-to-right Blalock-Taussig shunt; $D I L V$, double-inlet left ventricle; TAPVR, total anomalous pulmonary venous return; $A S D$, atrial septal defect; $D I R V$, double-inlet right ventricle; $A S$, aortic stenosis; $H L H S$, hypoplastic left heart syndrome; $A V S D$, atrioventricular septal defect; $I V S$, intact ventricular septum; $P F O$, patent foramen ovale; $V A$, ventriculoatrial; $P D A$, patent ductus arteriosus; $R P A$, right pulmonary artery; $P A$, pulmonary artery; $R V O T$, right ventricular outflow tract; $D O P$, dopamine; $E P I$, epinephrine; $N O R$, norepinephrine; $D O B$, dobutamine; ISP, isoproterenol; $A M R$, amrinone; $N$, newborn.

between the CAVH and CVVH populations. The patients undergoing CAVH required an average of 2.6 filters during treatment, whereas an average of 2.9 filters were used in the patients undergoing CVVH. However, because the therapy lasted longer in the CVVH group, the average cost of filters per patient-day was less. At an average filter cost of $\$ 40$, the cost for filters per patient-day was $\$ 43$ for those children undergoing CAVH and $\$ 23$ for those managed with CVVH.

Several electrolyte and hematologic abnormalities were common to all forms of renal replacement therapy (Table V). Hypokalemia and hypophosphatemia were experienced by the majority of individuals, regardless of which renal replacement therapy they received. Additionally, many patients in each group had a fall in platelet count after the institution of therapy. The development of hypothermia, with temperatures recorded at $34.5^{\circ}$ to $36^{\circ} \mathrm{C}$, was seen only in the patients receiving CVVH. Other complications recorded were as follows: in PD, failure of dialysate drainage in three patients, peritonitis in two patients, increasing chest tube losses in two patients and hyperglycemia in one patient. Hemorrhage was recorded for two patients undergoing CAVH and
Table IV. Values before and after therapy for caloric intake expressed as percent change from baseline before therapy

\begin{tabular}{lccc}
\hline & \multicolumn{1}{c}{$P D$} & CAVH & $C V V H$ \\
\hline Calories $(\mathrm{kcal} / \mathrm{kg})$ & & & \\
$\quad$ Pre & $24.2 \pm 2.42$ & $13.5 \pm 1.85$ & $20.5 \pm 5.2$ \\
Post & $32.4 \pm 3.7$ & $79.5 \pm 15.6$ & $76.4 \pm 5.0$ \\
$\quad \%$ change & $42.8 \pm 12.3$ & $515 \pm 130$ & $409 \pm 110$ \\
Urea (mmol/L) & & & \\
$\quad$ Pre & $17.4 \pm 2.5$ & $22.5 \pm 2.42$ & $25.5 \pm 3.7$ \\
Post & $18.1 \pm 2.0$ & $13.5 \pm 2.37$ & $14.2 \pm 1.83$ \\
\% change & $21.5 \pm 13.5$ & $-36.4 \pm 11.3$ & $-39.2 \pm 7.0$ \\
Creatinine $(\mu \mathrm{mol} / \mathrm{L})$ & \multicolumn{4}{c}{} \\
$\quad$ Pre & $184.5 \pm 22.3$ & $162 \pm 43.0$ & $205.2 \pm 14.8$ \\
Post & $194.1 \pm 18.0$ & $122 \pm 30.7$ & $136.6 \pm 13.4$ \\
$\quad \%$ change & $16.6 \pm 9.1$ & $-18.8 \pm 15.2$ & $-33.4 \pm 4.4$ \\
\hline
\end{tabular}

Values are mean \pm standard error of the mean.

limb ischemia for one. Superior vena caval thrombosis complicated the course of one patient having CVVH.

\section{Discussion}

This study confirms the previously reported high mortality in patients with acute renal failure requiring renal replacement therapy after cardiopulmonary bypass. The objective of renal replacement 
CALORIC INTAKE

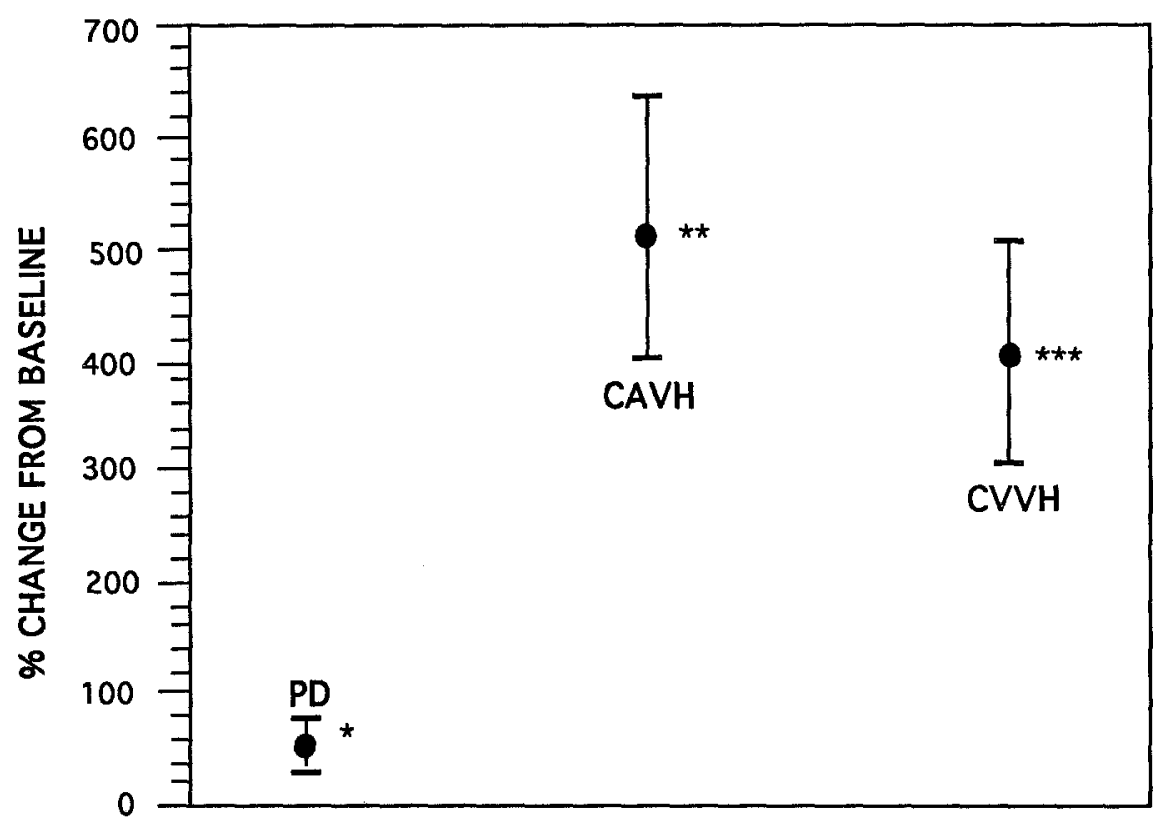

Fig. 1. Percent change in caloric intake from baseline after institution of renal replacement therapy. ${ }^{*} p=$ $0.01 ; * * p=0.003 ;{ }^{* * *} p=0.0001$.

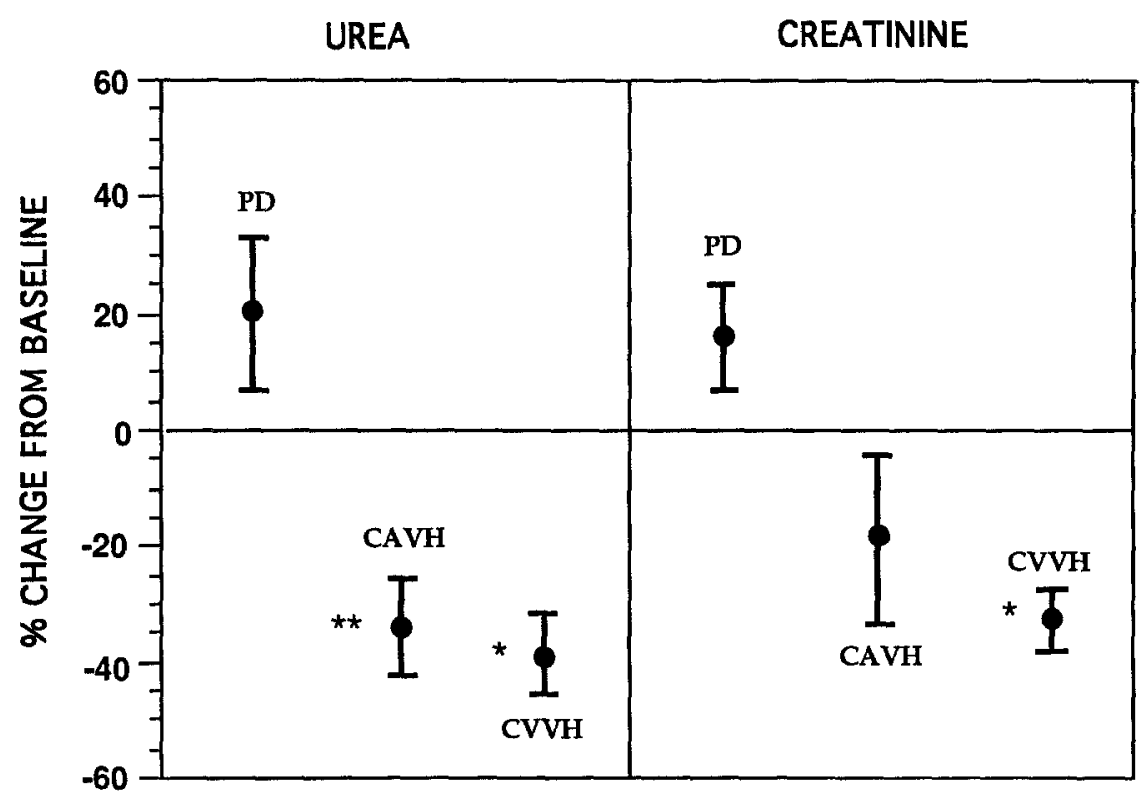

Fig. 2. Percent change from baseline value of urea (left panel) and creatinine (right panel) after initiation of renal replacement therapy. ${ }^{*} p=0.02 ;{ }^{*} p=0.005$.

therapy is to interrupt the cycle of fluid retention and tissue edema, which if not reversed rapidly spirals downhill to death from sepsis and multiorgan failure. In addition, a successful management strat- egy for these patients demands that the issue of the continuing negative nitrogen balance be addressed. Although PD can be effective in removing fluid, poor perfusion of the peritoneal membrane or leak- 
age around the catheter site rarely results in removal of enough free water to allow for adequate alimentation. The advantage of the hemofiltration techniques is that they allow for greater control of fluid balance, which is dependent only on the hydrostatic pressure gradient in the case of CAVH and independent of hydrostatic pressure in the case of CVVH. In the 42 patients studied in this series, volume overload and tissue edema were a major problem, in part because of the inevitable fluid retention associated with cardiopulmonary bypass as well as a persisting low cardiac output state. The objective of achieving a large negative fluid balance was more consistently realized in the hemofiltration groups than in the PD group. Although the average fluid deficit per hour was greater in the CAVH group, more patients in the CVVH group reached a goal of net negative fluid balance. This reflected the need to give fluid boluses to those patients treated by CAVH to maintain hemodynamic stability. It has been suggested that removal of this excess fluid in the immediate postoperative period may positively influence the patient's hemodynamic and ventilatory status. ${ }^{19,31}$ More important, this tight control of fluid balance allowed for a large calorie intake and a positive nitrogen balance in the patients managed with hemofiltration compared with the modest increases in those managed with PD. The importance of maintaining a high calorie intake in patients with oliguric renal failure after surgical procedures was demonstrated in a recent study by Bartlett and associates, ${ }^{32}$ in which energy expenditure was measured by indirect calorimetry. Those patients who had a positive energy balance (positive calorie balance) had a significantly lower mortality than patients with a negative energy balance $(9.4 \%$ versus $37.5 \%$ ). Finally, in this study with urea and creatinine used as markers of solute clearance in renal replacement therapy, both forms of hemofiltration were shown to be more effective than PD.

Several trends were evident from the demographic data gathered in this series. First, the patients in the hemofiltration groups tended to be older than those in the PD group. This is most likely a reflection of the need to establish additional vascular access in the hemofiltration groups, and this is at best difficult to achieve in young patients, leading to the bias of selecting older patients for this treatment who may have easier vascular access. However, both hemofiltration groups included young patients ( $<4$ weeks of age) who successfully underwent this form of renal replacement therapy.
Table V. Comparison of complications for each form of renal replacement therapy

\begin{tabular}{|c|c|c|c|c|c|c|}
\hline \multirow[b]{2}{*}{ Complication } & \multicolumn{2}{|c|}{$P D$} & \multicolumn{2}{|c|}{$C A V H$} & \multicolumn{2}{|c|}{$\mathrm{CVVH}$} \\
\hline & No. & $\%$ & No. & $\%$ & No. & $\%$ \\
\hline $\begin{array}{l}\text { Hypokalemia } \\
\left(\mathrm{K}^{+}<3.5 \mathrm{mmol} / \mathrm{L}\right)\end{array}$ & 13 & 76 & 7 & 87 & 5 & 55 \\
\hline $\begin{array}{l}\text { Hypophosphatemia } \\
\left(\mathrm{PO}_{4}<\text { normal lower }\right. \\
\text { limit) }\end{array}$ & $11^{*}$ & 92 & 8 & 100 & 9 & 100 \\
\hline $\begin{array}{l}\text { Thrombocytopenia } \\
\text { (fall to }<50,000 \times \\
10^{9} / \mathrm{L} \text { ) }\end{array}$ & 5 & 29 & 4 & 50 & 3 & 33 \\
\hline $\begin{array}{l}\text { Hypothermia } \\
\text { (core temp. }<36^{\circ} \mathrm{C} \text { ) }\end{array}$ & 0 & 0 & 0 & 0 & 4 & 44 \\
\hline
\end{tabular}

${ }^{*}$ Data available on 12 patients.

Second, there was a difference in the time to initiation of renal replacement therapy. PD was started earlier than CAVH or CVVH, possibly reflecting a hesitation to embark on a newer form of renal replacement therapy being introduced to the pediatric ICU, combined with the aforementioned need to obtain additional vascular access. When using CVVH in infants, we found that the preferred site of vascular access for the double-lumen catheter was in the right internal jugular vein with the tip advanced to the right atrium, which provided excellent flow with little resistance. In older children adequate flows could be achieved with the catheter placed in the inferior vena cava via the femoral vein. Finally, the patients in all three groups appeared to have a similar severity of illness, the vast majority requiring inotropic support, and many in all three groups required two or more inotropic drugs. However, postoperative sepsis was less prevalent in the PD group. These patients were in the pediatric ICU for a shorter time before starting dialysis, and it is recognized that prolonged stays in the ICU with multiple lines leads to an increased risk of infection.

The complications encountered in all three patient populations were similar. Although electrolyte changes, bleeding, and thrombosis are most likely directly attributable in large part to the renal replacement therapy, the thrombocytopenia seen was probably due to multiple causes and has been previously reported to be associated with acute renal failure after corrective cardiac operations in children. ${ }^{5}$ Besides renal replacement therapy, other causes of thrombocytopenia include sepsis and platelet consumption and destruction on intracardiac patches and valves. Hypothermia was identified as a problem in the CVVH group, but this problem 
was eliminated after institution of a blood warmer in the return limb of the CVVH circuit. One case of vascular thrombosis was identified in the $\mathrm{CVVH}$ group, which may have resulted from a previously placed central line. We did not routinely perform ultrasonic examinations on the venous access sites to look for thrombus, because we anticipated that the high flow of heparinized blood would make intravascular clot formation unlikely. Obviously this becomes an important issue for patients undergoing cavopulmonary shunts or Fontan procedures, of whom there were three in our series.

When the efficacy and complications of the two forms of hemofiltration are compared, CVVH appears to have distinct advantages over CAVH. The ability of the physician to exercise precise control over fluid balance by using pumped control of all input and output (except urine and insensible losses) in the former system may have led to a higher hemodynamic stability of the CVVH group and a lower need for extra boluses of volume. This consideration, combined with the additional arterial access needed for CAVH and the documented short- and long-term problems resulting from this access in children, ${ }^{33}$ has led to $\mathrm{CVVH}$ being adopted as the primary hemofiltration method. Additionally, the filter cost was less in the CVVH group and filter clotting was reduced in the artificially pumped circuit. Although this series is too small for any comparison of outcomes to be done, it is worth noting that in a recent randomized study that compared outcomes in adult patients with acute renal failure between pumped and nonpumped forms of hemofiltration, the survival was significantly better in the former ( $29 \%$ versus $13 \%){ }^{34}$

Despite the fact that both CAVH and CVVH have been successful in achieving fluid removal, improving biochemical status, and allowing for higher caloric intake, we have not been able to significantly reduce mortality from acute renal failure. This may reflect a certain reluctance to institute early and aggressive treatment. Two recent studies have appeared in the literature citing lower mortality rates than the generally quoted $50 \%$ to $70 \%$ for patients with acute renal failure requiring renal replacement therapy after cardiac operations. Book and associates ${ }^{13}$ reported on a group of 15 patients managed with early institution of high-volume rapidly cycled PD with a mortality rate of $33 \%$, and Zobel and colleagues ${ }^{19}$ reported on 11 patients treated with the early institution of CAVH or slow continuous ultrafiltration in whom the mortality rate was $28 \%$. In both groups all patients began receiving renal support within 48 hours of the operation and possibly during a period of renal insufficiency rather than overt renal failure. A recent report from $\mathrm{Mee}^{31}$ supports the notion of early institution of therapy to improve renal perfusion and decreased fluid overload, particularly in patients with right-sided failure with the use of a PD catheter placed at the time of the operation and used initially as a device to drain abdominal fluid. In the presence of oliguria resistant to diuretics or hyperkalemia, the system is changed to dialysis with brief cycles and modest volumes of PD fluid $(10 \mathrm{ml} / \mathrm{kg})$. These studies together with our results suggest that earlier intervention and more aggressive treatment of fluid overload and nutritional depletion may result in a decrease in mortality in acute renal failure.

\section{REFERENCES}

1. Guiffre RM, Tam KH Williams WG, Freedom RM. Acute renal failure complicating pediatric cardiac surgery: a comparison of survivors and nonsurvivors following acute peritoneal dialysis. Pediatr Cardiol 1992;13:208-13.

2. Hanson J, Loftness S, Clarke D, Campbell D. Peritoneal dialysis following open heart surgery in children. Pediatr Cardiol 1989;10:125-8.

3. Shaw NJ, Brocklebank JT, Dickinson DF, Wilson N, Walker DR. Long-term outcome for children with acute renal failure following cardiac surgery. Int $\mathrm{J}$ Cardiol 1991;31:161-6.

4. Baxter P, Rigby ML, Jones ODH, Lincoln C, Shinebourne EA. Acute renal failure following cardiopulmonary bypass in children: results of treatment. Int $\mathbf{J}$ Cardiol 1985; 7:235-9.

5. Rigden SPA, Barratt TM, Dillon MJ, de Leval M, Stark J. Acute renal failure complicating cardiopulmonary bypass surgery. Arch Dis Child 1982;57:42530.

6. Hilberman M, Myers BD, Carrie BJ, Derby G, Jamison RL, Stenson EB. Acute renal failure following cardiac surgery. J Thorac CARDIOVASC SuRg 1979;77: 880-8.

7. Bhat JG, Gluck MC, Lowenstein J, Baldwin DS. Renal failure after open heart surgery. Ann Intern Med 1976;84:677-82.

8. Abel RM, Buckley MJ, Austen WG, Barnett GO, Beck CH, Fischer JE. Acute postoperative renal failure in cardiac surgical patients. J Surg Res 1976; 20:341-8.

9. Abel RM, Buckley MJ, Austen WG, Barnett GO, Beck CH, Fischer JE. Etiology, incidence, and prognosis of renal failure following cardiac operations. J ThORAC Cardiovasc SuRg 1976;71:323-33.

10. Balfe JW. Peritoneal dialysis. Holliday MA, Barratt 
TM, Vernier RL, eds. Pediatric nephrology. 2nd ed. Baltimore, Williams \& Wilkins, 1987:814-27.

11. Gomez-Campdera FJ, Maroto-Alvaro E, Galinanes M, Garcia E, Duarte J, Rengel-Aranda M. Acute renal failure associated with cardiac surgery. Child Nephrol Urol 1988-89;9:138-43.

12. Chesney RW, Kaplan BS, Freedom RM, Haller JA, Drummond KN. Acute renal failure: an important complication of cardiac surgery in infants. $\mathrm{J}$ Pediatr 1975;87:381-8.

13. Book K, Ohqvist G, Björk VO, Lundberg S, Settergren G. Peritoneal dialysis in infants and children after open heart surgery. Scand J Thorac Cardiovasc Surg 1982;16:229-33.

14. Hodson EM, Kjellstrand CM, Mauer SM. Acute renal failure in infants and children: outcome of 53 patients requiring hemodialysis treatment. J Pediatr 1978;93: 756-61.

15. Kramer P, Wiggen W, Rieger J, Mathaei D, Scheler F. Arteriovenous hemofiltration: a new and simple method for treatment of overhydrated patients resistant to diuretics. Klin Wochenschr 1977;55:1121-2.

16. Paret G, Cohen AJ, Bohn DJ, et al. Continuous arteriovenous hemofiltration after cardiac operations in infants and children. J THORAC CARDIOvasC SuRG 1992;104:1225-30.

17. Jenkins RD, Harrison HL, Jackson EC, Funk JE. Continuous renal replacement in infants and toddlers. Contrib Nephrol 1991;93:245-9.

18. Zobel G, Ring E, Kuttnig M, Grubbauer HM. Five years experience with continuous extracorporeal renal support in paediatric intensive care. Intensive Care Med 1991;17:315-9.

19. Zobel G, Stein JI, Kuttnig M, Beitzke A, Metzler H, Rigler B. Continuous extracorporeal fluid removal in children with low cardiac output after cardiac operations. J Thorac Cardiovasc Surg 1991;101:593-7.

20. DiCarlo JV, Dudley TE, Sherbotie JR, Kaplan BS, Costarino AT. Continuous arteriovenous hemofiltration/dialysis improves pulmonary gas exchange in children with multiple organ system failure. Crit Care Med 1990;18:822-6.

21. Lopez-Herce J, Dorao P, Delgado MA, Espinosa L, Ruza F, Martinez MC. Continuous arteriovenous haemofiltration in children. Intensive Care Med 1989; 15:224-7.

22. Lieberman K. Continuous arteriovenous hemofiltration in children. Pediatr Nephrol 1987;1:330-8.
23. Bishof NA, Welch TR, Strife F, Ryckman FC. Continuous hemodiafiltration in children. Pediatrics 1990; 85:819-23.

24. Leone MR, Jenkins RD, Golper TA, Alexander SR. Early experience with continuous arteriovenous hemofiltration in critically ill pediatric patients. Crit Care Med 1986;14:1058-63.

25. Canaud B, Garred LJ, Christol J-P, Aubas S, Beraud JJ, Mion C. Pump assisted continuous venovenous hemofiltration for treating acute uremia. Kidney Int 1988;33:S154-6.

26. Yorgin PD, Krensky AM, Tune BM. Continuous venovenous hemofiltration. Pediatr Nephrol 1990;4: 640-2.

27. Lettgen B, Bonzel KE, Colombo JP, et al. Therapie der Hyperammonämie bei Carbamylphosphat-Synthetasemangel mittels Peritonealdialyse und venovenöser Hämofiltration. Monatsschr Kinderheilkd 1991;139:612-7.

28. Thompson GN, Butt WW, Shann FA, et al. Continuous venovenous hemofiltration in the management of acute decompensation in inborn errors of metabolism. J Pediatr 1991;118:879-84.

29. Ellis EN, Pearson D, Robinson L, Belsha CW, Wells TG, Berry PL. Pump assisted hemofiltration in infants with acute renal failure. Pediatr Nephrol 1993;7: 434-7.

30. Barton IK, Hilton PJ. Veno-venous haemofiltration in the intensive care unit. Clinical Intern Care 1993;4: $16-22$.

31. Mee RBB. Dialysis after cardiopulmonary bypass in neonates and infants. J Thorac Cardiovasc Surg 1992;103:1021-2.

32. Bartlett RH, Mault J, Dechert RE, Palmer J, Swartz RD, Port FK. Continuous arteriovenuous hemofiltration: Improved survival in surgical acute renal failure? Surgery 1986;100:400-8.

33. Park SC. Complications associated with cardiac catheterization. Neches WH, Park SC, Zuberbuhler JR, eds. Perspectives in pediatric cardiology. volume 3. Mount Kisco, NY: Futura, 1991:203-14.

34. Storck M, Hartl WH, Zimmerer E, Inthorn D. Comparison of pump driven and spontaneous continuous hemofiltration in postoperative acute renal failure. Lancet 1991;337:452-5. 